\title{
Accounting for surveillance
}

\author{
Article
}

Accepted Version

Jones, R. H. (2020) Accounting for surveillance. Journal of Sociolinguistics, 24 (1). pp. 89-95. ISSN 1360-6441 doi: https://doi.org/10.1111/josl.12405 Available at https://centaur.reading.ac.uk/88025/

It is advisable to refer to the publisher's version if you intend to cite from the work. See Guidance on citing.

To link to this article DOI: http://dx.doi.org/10.1111/josl.12405

Publisher: Wiley

All outputs in CentAUR are protected by Intellectual Property Rights law, including copyright law. Copyright and IPR is retained by the creators or other copyright holders. Terms and conditions for use of this material are defined in the End User Agreement.

\section{www.reading.ac.uk/centaur}

\section{CentAUR}

Central Archive at the University of Reading

Reading's research outputs online 


\title{
Accounting for surveillance
}

\author{
Rodney H. Jones \\ University of Reading
}

2019

Jones, R. (in press) Accounting for surveillance. Journal of Sociolinguistics. https://doi.org/10.1111/josl.12405 Published online Dec 13, 2019

\begin{abstract}
This contribution discusses the ways people hold themselves and others accountable for everyday practices of surveillance. It analyses three examples: (1) the "breeching experiments" of the video artist "Surveillance Camera Man," (2) a "stop and frisk" incident involving a 17-year-old boy in Harlem, and (3) the pop-up windows on websites that ask for users' consent to use "cookies." Understanding the relationship between language and securitization, it is argued, requires that we pay attention to the interactional basis of surveillance and the ways rights and responsibilities are negotiated, ratified, challenged, or ignored in the moment-by-moment unfolding of communication.
\end{abstract}

A few weeks ago I came across an op-ed piece in the New York Times by tech writer Karen Swisher (2019) entitled: 'We're not going to take it anymore,' arguing that it's time for the US to follow Europe in passing tough legislation to make internet companies accountable for the way they relentlessly gather data about us. Since I was accessing the article from the UK (which is, for now, part of Europe), in order to read it I had to engage in an interaction, mandated by the EU's General Data Protection Regulation (GDPR), in which I was asked to agree to allow the installation of cookies on my computer to enable its owners to relentlessness gather data about me. The goal of the law is to make the Times accountable by forcing them to elicit my consent for gathering my data. But the result of the interaction was 
to make me accountable — as soon as I clicked 'agree', I was the one who took responsibility for allowing the surveillance to commence.

To my mind, the most productive intervention Rampton and Charalambous make in their introduction to this discussion is their attempt to draw our attention to the relationship between the macro structures of power around securitization and their instantiation in everyday social interaction, and nowhere is this relationship more evident than in the way people navigate the infrastructures of accountability around everyday practices of surveillance. Practices such as agreeing to allow cookies to be deposited on my computer may not rise to level of the terrorist alerts, cross border conflicts and widespread programs of government surveillance one usually thinks of in the context of (in)securitization. My argument here, picking up the thread offered by Rampton and Charalambous (as well as Rampton \& Eley, 2018), is that where sociolinguistics can make its most useful contribution to this debate is in helping us to understand how these broader contexts of (in)securitzation are dependent on the everyday architectures of social interaction through which we manage our social relationships. 'Governing' Rampton and Charalambous remind us 'entails social interaction,' and so solutions to abuses of power don't just lie in the principles of 'rights' and 'responsibilities' that form the basis of most privacy laws, but require that we pay attention to the interactional basis of surveillance (Jones, 2017; Rampton \& Eley, 2018), the ways these rights and responsibilities are negotiated, ratified, challenged or ignored in the moment by moment unfolding of communication.

Making infrastructures of accountability explicit 
One way to attend to this is through the study of the ways people account for practices of surveillance. In International Relations theory informed by the Copenhagen school, securitization itself might be regarded as a means of discursively constructing accounts around extraordinary measures taken by those in power to 'protect' citizens from perceived threats. When I speak of accounts, however, I am not just referring to the need for people to justify or legitimate practices of surveillance, but am using the term in the ethnomethodological sense in which 'being accountable' for our actions and utterances forms the basis for the way people jointly make sense of their social worlds (Garfinkel, 1967). All interactions unfold within certain infrastructures of accountability - social expectations about the rights and responsibilities of different participants and about what to do when these expectations are breeched. From this perspective, mundane social interactions serve as sites where larger social-moral orders are constituted and reproduced through the moment by moment negotiation, ratification and contestation of infrastructures of accountability.

When it comes to issues of surveillance and privacy, sometimes what should be accounted for and who should do the accounting are mandated by laws like the GDPR. But in most everyday situations, infrastructures of accountability are implicit, only made visible when social norms about who has the right to watch whom under what circumstances are violated. This, in fact, was the point of Garfinkel's (1967) classic 'breeching experiments', interventions in which experimenters engaged in intentionally 'abnormal' behavior in public in order to compel the 'victims' of such behavior to articulate the infrastructures of accountability governing the situation. An example of such breeching experiments can be seen in the work of Surveillance Camera Man1, a YouTube artist who wanders around public spaces taking videos of people without their consent and recording their reactions. Below are two brief excerpts from one of his videos: 


\section{Excerpt 1}

$1 \quad$ Student: $\quad$ whaddaya doin $\uparrow(0.4)$

2 SCM: I'm just taking a video (0.4)

$3 \quad$ Student: $\quad$ why:: are you taking a video without asking us $\uparrow \downarrow$

$4 \quad$ SCM: $\quad$ what $\downarrow \uparrow(0.2)$

5 Student: $\quad$ shouldn't you ASK us first $\uparrow$ before taking a video $\downarrow \uparrow$ (1.0)

$6 \quad$ SCM: $\quad$ oh you seem confused $\downarrow$ (1.1)

$7 \quad$ Student: $\quad$ yeah you're not (.) we:: have this room $\downarrow$ and you just like barge in $\uparrow \downarrow$

$8 \quad$ SCM: $\quad(0.4)$ oh $(1.1)$

9 Student: can you leave $\downarrow \uparrow$ (1.0) DUDE (.) what's your problem can you just

$10 \quad$ leave $\downarrow \uparrow$

$11 \quad \mathrm{SCM}: \quad \operatorname{huh} \uparrow(0.4)$

12 Student: can you ask us why $\uparrow$ you're taking the video $\downarrow \uparrow(0.4)$

13 SCM: I'm just takin a video $\downarrow(0.7)$

14 Student: okay (.) well I don’t want:: to be taken a video of $\uparrow$ (1.1)

15 SCM: why are you so WORried about it $\downarrow$

16 Student: I'm NOT WORried (.) you're just being anNOYing $\downarrow$

\section{Excerpt 2}

21 Teacher: who are you and why are you taking our photo $\downarrow(0.4)$

22 SCM: oh I'm taking a video (0.7)

23 Teacher: why $\uparrow \downarrow=$

24 Student: =why (.) hehehe=

25 SCM: $\quad$ what $\downarrow \uparrow$ (.) why [not 
26 Teacher:

[is what we're asking (.) you don't have permission

$$
\text { to } \uparrow(0.5)
$$

28 SCM: oh $(0.2)$

29 Teacher: $\quad$ we're not free subjects $(0.4)$ you ask $\downarrow(0.3)$

30 SCM: huh (.) okay $(0.1)$

31 Teacher: that's usually how that works

32 SCM: $\quad$ nah it's it's fine (.) I'm just takin a video (0.3)

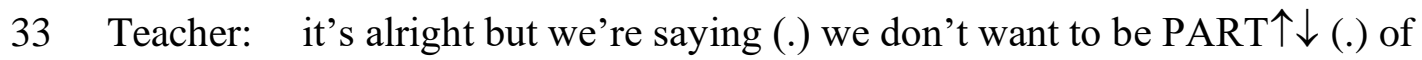

34 that video $=$

35 SCM: $\quad=$ oh

36 Teacher: and that's our choice $\downarrow$ (.) it's a private class $\downarrow \uparrow$ room and people have paid for this time $\downarrow$

By refusing to be accountable for his behavior, Surveillance Camera Man compels his victims to articulate the principles underlying their claims not to be surveilled - the main one being that of a certain reciprocity in monitoring rights expected by people in symmetrical relationships: the problem is not so much the surveillance but the fact that the surveiller has not elicited the consent of the surveilled. The second key principle articulated has to do with individuals' rights to control the boundaries of what Goffman (1971) calls 'territories of the self', in both cases depicted as physical spaces to which the victims claim 'ownership' ('we:: have this room $\downarrow$ and you just like barge in $\uparrow \downarrow$ '; 'it’s a private class $\downarrow \uparrow$ room and people have paid for this time $\downarrow$ '). Both of these principles - the principle of consent and the principle of territorial integrity, are, in fact, the basis of legal definitions of privacy in most 'Western' nations, rooted in liberal democratic ideas about individual autonomy, egalitarianism, and the sanctity of 'private property'. 
Challenging surveillance in police stops

Infrastructures of accountability also become visible in situations in which people challenge the norms surrounding surveillance, as was the case with Alvin, a 17-year-old boy in Harlem who surreptitiously recorded himself challenging police officers' practice of searching him2. Here is a brief except from his recording:

\section{Excerpt 3}

$1 \quad$ O1: Oh YOU again man $\downarrow \uparrow \quad(0.1)$

2 A: I was I just got stopped like [two blocks ago

3 O1: [you know why $\uparrow$ (.) you look very suspicious=

4 A: $=$ cos you're always [looking ] I'm CRAZY=

5 O1: [it's ahh ] =it's because you keep

6 it's because you keep looking back at us man [(inaudible)

7 A: $\quad[C O S$ you always you're

$8 \quad$ always looking crazy yo

9 O2: [why does he have an empty

10 bookbag?

11 A: comin up the block always $\uparrow \downarrow$

12 O2: It's because that's our job man (0.1) it's our [job (inaudible)

13 A: [to stare at $\mathrm{me} \uparrow=$

$14 \mathrm{O} 1:=$ listen to me (0.5) listen to me (2.5) our job is to look for suspicious 
15 behavior (.) when you keep looking at us like that (.) lookin back=

16 A: =cos you're always like sta (.) I just got [ stopped like] two blocks away=

17 O2: $\quad$ [put your hands up

18 O1: =because $\uparrow \downarrow$ you keep DOIN that shit man (.) we stopped you last time

19 because

20 A:

[you]

21 O1: listen to me (0.8) when you're walking the block with your hood up and you

22 keep looking back at us like that $\uparrow$

23 O2: why do you have a fuckin empty [bookbag

24 O1: [we think you might have somethin

In contrast to Surveillance Camera Man, police officers are normally permitted to openly monitor citizens in public and under certain conditions to search them, a fact that the officers make clear in their account ('It's because that's our job man'). What is interesting here, though, is that the main thrust of the account is a counter-challenge: the officers are surveilling Alvin because he was surveilling them - echoing a protocol that Sacks (1972: 287) observed in his study of police stops; 'Those who treat the presence of the police as other than normal are themselves seen as other than normal.' Apparently, all rights to individual autonomy are forfeited as soon as one is marked as 'other than normal', and Alvin's attempt to suggest a reciprocity of monitoring rights results in the threat of arrest:

\section{Excerpt 4}

46 O1: You wanna go to jail $\downarrow \uparrow$

47 A: wha bo wha what for $\uparrow \downarrow$

$48 \quad$ O2: SHUT [your FUCKIN mouth $\downarrow$ 
49 A: $\quad[$ what for $\uparrow \downarrow=$

50 O2: = shut you fuckin MOUTH [kid

51 A: $\quad$ [for (.) what am I being arrested for $\downarrow=$

52 O1: = for bein a fuckin mutt $\downarrow$ you know [that $\uparrow$

53 A: $\quad$ [oh so

$54 \quad$ that's a law $\downarrow \uparrow$ (.) gettin (.) being a mutt $\uparrow(0.9)$

55 O1: who the fuck do you think your talkin to $\downarrow$

At this point, infrastructures of accountability based on 'rights' and 'responsibilities', whether they involve the principles of consent and autonomy articulated in the first two excerpts, or principles of 'justified suspicion' and 'probable cause' articulated in excerpt 3, or even whether or not there is a legal basis for the threat of arrest, break down. Because, the fact is, despite these infrastructures, in most situations such as this, what really matters is the raw exercise of power officers are able to engage in in the moment (regardless of how they may or may not be called on to account for it later).

Clicking 'Continue with cookies'

At first glance there may not seem to be much of a resemblance between the examples above and dialogue windows such as that shown in Figure 1 that pop up on our screens on a daily basis, but such windows also constitute everyday instances of surveillance for which parties are called on to be accountable. The primary aim of the GDPR is to enforce the kinds of infrastructures of accountability articulated in excerpts 1 and 2, based on principles of consent and autonomy. In order to conduct surveillance on me (via a cookie deposited on my 
computer), this website must inform me why they wish to do this and the purposes for which my data will be used, and must elicit my explicit consent (through, in this case, getting me to click on a button that says 'Continue with Recommended Cookies'). These principles are really only upheld, however, if you regard this window as a text, something like a contract that people read and sign, rather than as an interaction, subject to all of the norms and contingencies that govern other interactions around surveillance such as Alvin's run-in with the police discussed above.

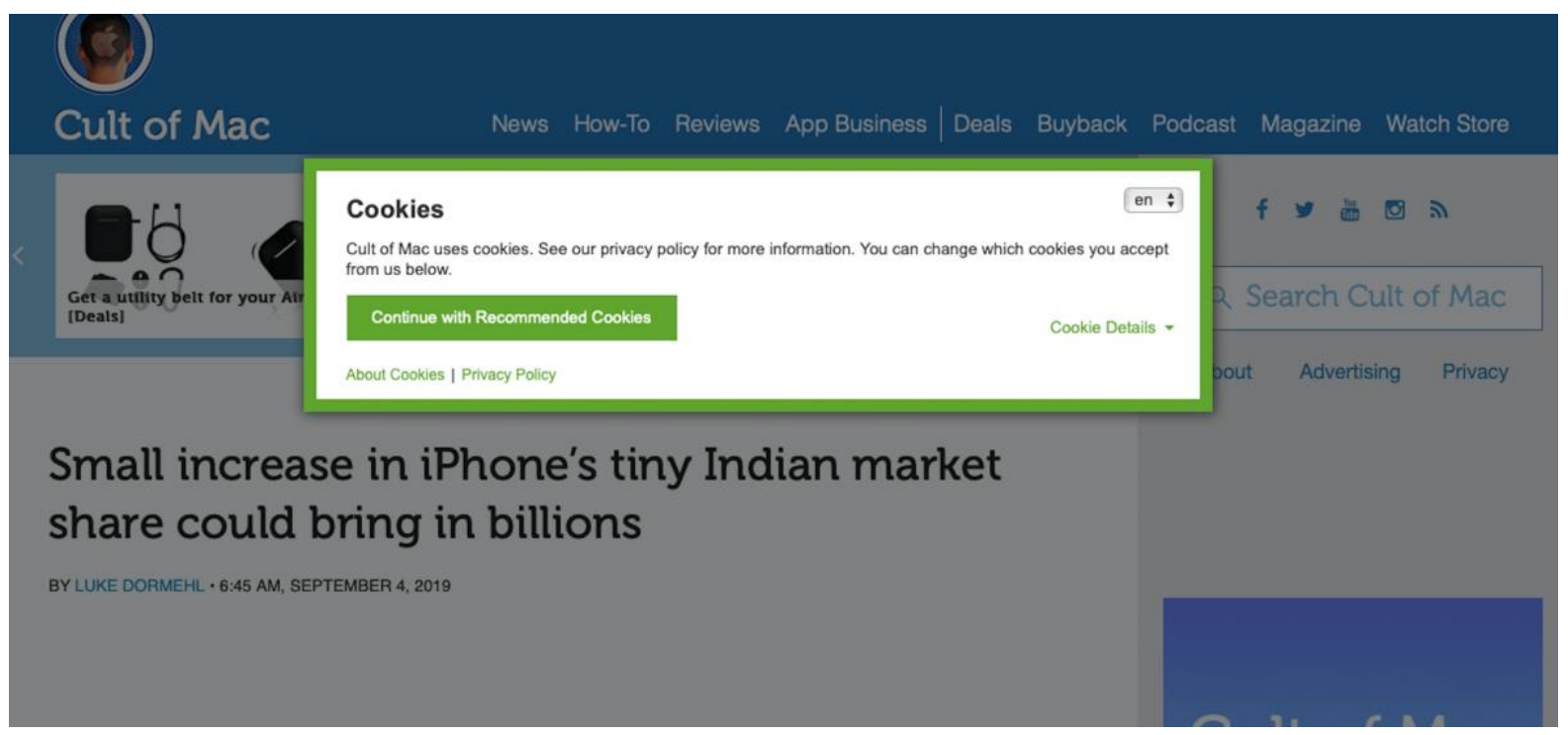

Figure 1: A 'clickwrap' contract

When viewed as an interaction it becomes clear that my choice to give consent is not much of a choice at all. First of all, there is no obvious alternative 'speech act' to 'Continue with Recommended Cookies'; opportunities to change the default recommendations are hidden behind a tiny piece of hypertext on the right side of the window that says 'cookie details'. Second, this request for consent has come just at the moment that I wish to read the article it obscures, and my ability to read it is contingent upon my consent, much like a citizen's wish 
to 'be on their way' often seems contingent on their consent to intrusive searches by police officers or security guards. In her book on wrap contracts, Kim (2013) points out that online clickwrap contracts such as these are designed in ways that make not reading the terms and conditions and not trying to adjust one's 'cookie preferences' the rational choice, since the cost of trying to understand the legal significance of these actions outweighs the prospective benefit.

But what makes such 'performances' of accountability most insidious is their everyday, iterative nature. As Derrida (1984) — and later Kristeva (1986)- have pointed out, the real force of most speech acts (including the speech act of securitization) comes not from the felicity conditions under which they are produced but from the sheer weight of their iterativity - the fact that they are performed over and over again. Every action of clicking 'I agree' makes it more likely that I will do the same next time, because 'I agree' has come to be the means by which I can be 'on my way'. In other words, rather than giving people more control over their data, the GDPR has more likely resulted in conditioning citizens to more readily -more automatically- relinquish control.

Situated dynamics along the thin line between protection and precarity

The point I am trying to make here is that sociolinguistics is uniquely situated to make a contribution to conversations about (in)securitization because of the tools it provides to analyse the dynamic, situated realization of (in)securitization in everyday social interaction. As Rampton and Charalambous point out, however, there is a danger of being perceived as trivializing (in)securitization in extraordinary contexts characterized by fear and precarity by 
pointing out its basis in more ordinary social interactions. But understanding the way fear and precarity affect social interaction in exceptional conditions can benefit from uncovering the way people deal with everyday micro moments of fear and precarity involved, for example, in dealing with small or large breeches of etiquette around who has the right to look at us or to take our picture. It is also good to remember that what for some people are practices relatively free of precarity, such as walking down the street, are, for others, sites of constant uncertainty in which at any moment they might be detained, accosted, searched, or even shot by the very agents of state security that promise to keep them safe. This, for them, constitutes the 'everyday'. Finally, what such an approach can reveal is that sometimes infrastructures of accountability based on enlightenment notions of autonomy and consent that are supposed to protect our privacy, when subjected to the contingences of interaction, can actually end up making it more likely that we become complicit to regimens of surveillance and securitization.

\section{Notes}

1 https://www.youtube.com/channel/UCLd-8dbneh6QHH2pd55u6kA

$2 \mathrm{https} / / / \mathrm{www}$.youtube.com/watch? $\mathrm{v}=7 \mathrm{rWtDMPaRD} 8$

\section{Transcription Conventions}

(0.1) pause (length in seconds indicated by number in parentheses)

(.) pause of less than 0.1 seconds

[] overlapping speech

$=\quad$ latching

$\downarrow \quad$ falling intonation 
$\uparrow \quad$ rising intonation

$\uparrow \downarrow \quad$ rising-falling intonation

$\downarrow \uparrow \quad$ falling-rising intonation stress/emphasis

CAPS shouting

\section{References}

Derrida, J. (1984), Margins of Philosophy (trans. A. Bass), Chicago: University of Chicago Press.

Garfinkel, H. (1967). Studies in Ethnomethodology. Englewood Cliffs, NJ: Prentice Hall.

Goffman, E. (1971). Relations in Public: Microstudies of the public order. New York: Harper \& Row.

Jones, R. (2017). Surveillant media: Technology, language and control. In C. Cotter and D. Perrin (eds.) The Routledge Handbook of Language and Media (pp. 244-261). London, Routledge.

Kim, N. S. (2013). Wrap Contracts: Foundations and Ramifications. Oxford: Oxford University Press.

Kristeva, J. (1986), Word, dialogue, and the novel, in T. Moi (ed.), The Kristeva Reader (pp. 35-61), New York: Columbia University Press.

Rampton, B. \& L. Eley (2018). Goffman \& the everyday interactional grounding of surveillance Working Papers in Urban Language \& Literacies \# 246. At academia.edu

Sacks, H. (1972). Notes on police assessment of moral character. In D. Sudnow (Ed.), Studies in Social Interaction (pp. 280-293). New York: Free Press.

Swisher, K. (2019, April 10). Opinion: We're Not Going to Take It Anymore. The New York Times. Retrieved from https://www.nytimes.com/2019/04/10/opinion/internet-privacyregulation.html 